\title{
SYNTHESIS, CHARACTERIZATION AND IN-VITRO RELEASE STUDY OF MUTUAL PRODRUGS OF MESALAMINE AND SULPHONAMIDES AS AZO COMPOUNDS
}

\author{
Shivaji Koshti \\ Deptt. of Chemistry, S. S. V. P. S's. L. K. Dr. P. R. Ghogrey Science College, Dhule, Maharashtra, India \\ *Corresponding author:smkoshti@rediffmail.com,smkoshti82@gmail.com
}

\begin{abstract}
Azo compounds studied as prodrugs of sulfacetamide and sulfathiazole were prepared by diazotization reaction in which sulfacetamide and sulfathiazole were coupled with salicylic acid. The newly synthesized azo compounds were inoculated with Pseudomonas aeruginosa bacterium species which secrete the azoreductase enzyme causing the release of the parent compound. These results have been utilized to propose that azoreductase enzyme acts for the reduction of - $\mathrm{N}=\mathrm{N}-$. The mechanism of the reaction is discussed on the basis of release in terms of the formation of compounds like sulfacetamide/sulfathiazole and mesalamine. The use of bacteria as an enzyme producing agent, and released compounds acting as the anti-ulcer agent can find a variety of applications for colon targeting agents in the field of medicinal chemistry.
\end{abstract}

Keywords: Sulfacetamide, Sulfathiazole, Azo compounds, Salicylic acid, Enzymatic degradation.

\section{INTRODUCTION}

There are some limitations to oral drug administration of any drug, because of its solubility, permeability and absorption properties [1]. There is one strategy to overcome the limitations associated with drug formulation, is to design a prodrug which is preferred approach adopted by drug companies [2, 3]. Newer sulfa drugs like sulfapyridine, sulfathiazole were reported and can be used to replace sulphanilamide; another prontosil drug [4]. Sulfonamides are compounds having a common $p$-aminophenyl ring moiety in their structure, differing in the substitution at the $\mathrm{N}$-position [5]. These agents inhibit the synthesis of folic acid in bacteria by forming a complex with enzyme [6], they are also used in the urinary tract infections, antiepileptic activity, anticonvulsant, cardiotonic activity [7, 8].

Azo compounds are widely used in the field of textile industries for dying the fibers, in pharmaceutical field for biomedical studies, because they have specific physico-chemical properties. Therefore, these are used in pharmaceuticals, cosmetics, and food industries extensively [9]. It inhibits the growth of gram-negative bacteria and gram-positive bacteria [10].

The human gut microflora contains numbers of different types of bacteria that biosynthesizes many enzymes, out of which one is azoreductase enzyme, which is responsible for metabolization of azo compounds, i.e. reduction of azo compounds to two primary aromatic amines [11].

5-Amino salicylic acid (Mesalamine) is used in the treatment of ulcerative colitis, inflammatory bowel syndrome (IBS) [12]. Its action is helping to stop the biosynthesis of prostaglandin [13,14] and also assumed to be an antioxidant [15]. The absorption of it, in the stomach and the upper intestine is prevented due to modification of it, which consequently reaches to the colon intact $[16,17]$.

Nearly $90 \%$ of the orally administered sulfa drugs absorbed and metabolized in uppermost part of GUT and in small intestine due to uneven $\mathrm{pH}$ environment, .For the purpose to reach at lower most part of GUT, the orally administered drugs are not employed due to this problem. But the prodrug approach is solving this problem at much extent. Making a mask to the drug which want to be employed at lower most part of GUT by using another drug or by other biocompatible agents. Then in suitable conditions and $\mathrm{pH}$ environment, the prodrug breaks enzymatically and release parent drug at lower most part of GUT.

By making azo prodrugs of sulfacetamide, sulfathiazole and salicylic acid does not absorbs at uppermost part of GUT and they successively reach at colon where they 
bifurcate and release parent drug. These azo compounds break in azoreductase enzyme and show their effects means here from one formulation we get two different benefits. Therefore, such type azo compounds may acts as mutual prodrugs for each other.

Therefore, all the medicinal properties of sulfacetamide, sulfathiazole and salicylic acid encouraged to undertake the synthesis of azo compounds that contains these moieties.

\section{EXPERIMENTAL}

\subsection{Material}

Pharmaceutical grade sulfa drugs (Ishita Drugs \& Pharmaceuticals, Ahmadabad, Gujarat, India) sulfathiazole and sulfacetamide were used. Sodium nitrite, sodium hydroxide, and salicylic acid were from SD fine chemicals Ltd. Mumbai, India. All other reagents and solvents were of analytical grade. The compounds were characterized by IR, ${ }^{1} \mathrm{H}$ NMR and ${ }^{13} \mathrm{C}$ NMR. The melting points were determined by the open capillary method and are uncorrected. The IR spectra were recorded on Perkin-Elmer spectrum-one FTIR instrument in the form of $\mathrm{KBr}$ pellet. The ${ }^{1} \mathrm{H}$ NMR and ${ }^{13} \mathrm{C}$ NMR were recorded in DMSO on a Bruker Avance II 400 NMR spectrometer using TMS as an internal standard. The purities of synthesized azo compounds were checked by TLC. The crude products were recrystallized from ethanol.

\subsection{Methods}

2.2.1. Procedure for synthesis of 5- (\{4-[(acetyl amino) sulfonyl]phenyl diazenyl)-2-hydrobenzoic acid (Compound A) [18-20]

A diazonium salt solution was prepared by mixing 2.14 $g$ of sulfacetamide $(0.01 \mathrm{~mol}), 2.5 \mathrm{ml}$ conc. $\mathrm{HCl}$ and freshly prepared $2.5 \mathrm{ml} \mathrm{NaNO}_{2}$ solution (4N) with constant stirring. The diazotization process was carried out over half an hour at $3-5^{\circ} \mathrm{C}$. This diazonium salt was added drop-wise at $3-5^{\circ} \mathrm{C}$ to a solution of $1.38 \mathrm{~g}(0.01$ mol) of salicylic acid and $1 \mathrm{~g}$ of $\mathrm{NaOH}$ in $10 \mathrm{ml}$ of distilled water. This coupling reaction mixture was stirred for more than half hour and the $\mathrm{pH}$ of the resultant mixture was adjusted to value 7 . After complete addition and stirring the mixture was kept overnight at room temperature. The formed azocolored compound was filtered, washed with cold water, and dried. The crude product was recrystallized in $70 \%$ ethanol after addition of ice-cold distilled water. Crystals with red color were separated out by filtration with a Buchner funnel and dried (83\% yield).

\section{Diazonium salt formation reaction}

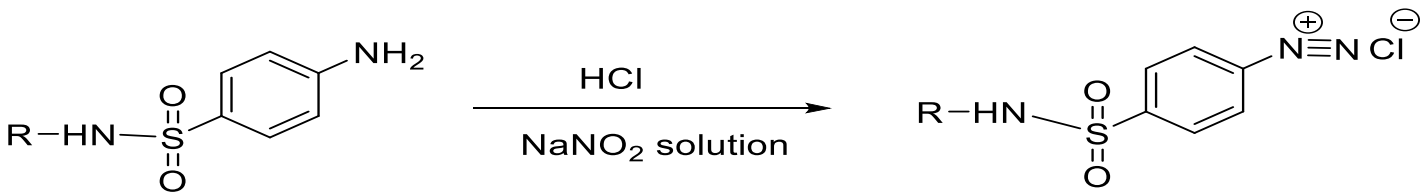

Sulphonamide

Diazonium Salt Coupling reaction<smiles>O=C(O)c1ccccc1O</smiles>

Salicylic acid

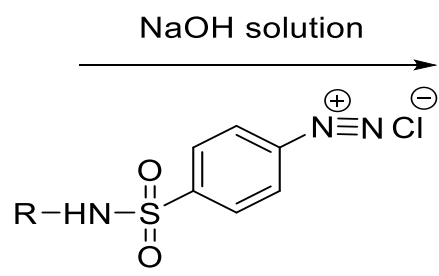

Where $-R$ is

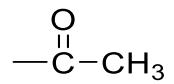

then Compound A

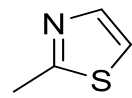

then Compound B

\section{Scheme of the reaction}




\subsubsection{Spectral Data of 5- (\{4-[(acetyl amino) sulfonyl/phenyl diazenyl)-2-hydrobenzoic acid (Compound $A$ )}

IR $(\mathrm{KBr}$ pellet $), v\left(\mathrm{~cm}^{-1}\right) 1325.14\left(-\mathrm{SO}_{2}-\right), 1444.73$ $(-\mathrm{OH}$ of $-\mathrm{COOH}), \quad 1579.75 \quad(-\mathrm{N}=\mathrm{N}-), \quad 1612.54$ $(>\mathrm{C}=\mathrm{O}), 3064.99(-\mathrm{NH}-), 3238.59(-\mathrm{OH}) ;{ }^{1} \mathbf{H}$ NMR (DMSO) $\delta(\mathrm{ppm}): 1.95\left(1 \mathrm{H},-\mathrm{CH}_{3}\right), 7.05(1 \mathrm{H}$, of salicylic acid), $7.75(1 \mathrm{H}$, of salicylic acid), $7.93(2 \mathrm{H}$, Ar-H of sulfacetamide), 7.99 (1H, of salicylic acid), $8.08(2 \mathrm{H}$, Ar- $\mathrm{H}$ of sulfacetamide), 8.34 (1H, of $-\mathrm{NH}-)$, $12.10(1 \mathrm{H}, \quad$ of $-\mathrm{COOH}),{ }^{13} \mathbf{C} \quad \mathbf{N M R} \quad(\mathrm{DMSO}) \delta$ $(\mathrm{ppm}): 23.18\left(-\mathrm{CH}_{3}\right), 113.48(\mathrm{Ar}-\mathrm{C},-\mathrm{COOH}), 118.83$ (Ar-C), 122.48 (Ar-C), 127.05 (Ar-C), 128.84 (Ar-C), 130.11 (Ar-C), 140.34 (Ar-C-SO $\left.2^{-}\right), 154.33$ (Ar-C$\mathrm{N}=\mathrm{N}-), 161.20(\mathrm{Ar}-\mathrm{C}-\mathrm{N}=\mathrm{N}-), 164.53(\mathrm{C}-\mathrm{OH}), 168.8$ $(\mathrm{C}-\mathrm{OOH}), 171.94(>\mathrm{C}=\mathrm{O})$.

\subsubsection{Procedure for synthesis of 2-hydroxy-5- (\{4- [(1,3-thiazo-2-ylamino)sulfonyl]phenyl\} diazenyl) benzoic acid (Compound B)}

A diazonium salt solution was prepared by mixing 2.55 $\mathrm{g}$ of sulfathiazole $(0.01 \mathrm{~mol}), 2.5 \mathrm{ml}$ conc. $\mathrm{HCl}$ and freshly prepared $2.5 \mathrm{ml} \mathrm{NaNO}_{2}$ solution (4N) with constant stirring. The diazotization process was carried out over half an hour at $3-5^{\circ} \mathrm{C}$. This diazonium salt was added drop-wise at $3-5^{\circ} \mathrm{C}$ to a solution of $1.38 \mathrm{~g}(0.01$ $\mathrm{mol}$ ) of salicylic acid and $1 \mathrm{~g}$ of $\mathrm{NaOH}$ in $10 \mathrm{ml}$ of distilled water. This coupling reaction mixture was stirred for more than half hour and the $\mathrm{pH}$ of the resultant mixture was adjusted to value 7 . After complete addition and stirring, the mixture was kept overnight at room temperature. The formed azocolored compound was filtered, washed with cold water, and dried. The crude product was recrystallized in $70 \%$ ethanol after addition of ice-cold distilled water. Crystals with red color were separated out by filtration with a Buchner funnel and dried (78\% yield).

\subsubsection{Spectral data of 2-hydroxy-5- (\{4-[(1,3-} thiazo-2-ylamino)sulfonyl Jphenyl $\}$ diazenyl) benzoic acid (Compound B)

IR ( $\mathrm{KBr}$ pellet), $v\left(\mathrm{~cm}^{-1}\right) 1325.14\left(-\mathrm{SO}_{2}^{-}\right), 1444.73$ (-OH of $-\mathrm{COOH}), 1581.68(-\mathrm{N}=\mathrm{N}-), 3063.06(-\mathrm{NH}-)$, $3266.66(-\mathrm{OH}),{ }^{1} \mathbf{H} \mathbf{N M R}(\mathrm{DMSO}) \delta(\mathrm{ppm}): 6.66(1 \mathrm{H}$, thiazole), $6.70(1 \mathrm{H}$, thiazole $), 7.19(1 \mathrm{H}$, salicylic acid $)$, $7.78(1 \mathrm{H}$, salicylic acid), $7.98(1 \mathrm{H}$, salicylic acid $), 8.00$ $(2 \mathrm{H}$, benzene ring of sulfathiazole), $8.17(2 \mathrm{H}$, benzene ring of sulfathiazole), $8.45(1 \mathrm{H},-\mathrm{NH}-), 14.97(1 \mathrm{H}$, $\mathrm{COOH}),{ }^{13} \mathbf{C} \mathbf{N M R}(\mathrm{DMSO}) \delta$ (ppm): 115.78 (for thiazole C), 116.87 (Ar-C), 119.51 (Ar-C), 122.15 (ArC), 130.33 (Ar-C), 131.96 (Ar-C), 145.00 ( $\mathrm{Ar}-\mathrm{C}-\mathrm{SO}_{2}$ ), 146.08 (Ar-C-N=N-), 153.90 (Ar-C-N=N-), 160.00 (thiazole, C-NH-), 161.68 (Ar-C-COOH), 173.80 $(-\mathrm{COOH})$.

\subsection{In-vitro azo reduction by Pseudomonas aeruginosa i.e. drug release studies [20]}

Pseudomonas aeruginosa was isolated from industrial effluent water samples collected from Disan Agro Ltd. Dhule (MS) India, by spreading diluted sample from $10^{-5}$ dilutions over a sterile Cetrimide Agar plate (per liter: enzyme digest of gelatin- 20g, Magnesium chloride- $1.4 \mathrm{~g}$, potassium chloride- $10 \mathrm{~g}$, Cetrimide (cetyltrimethylammoniumbromide)- $0.3 \mathrm{~g}$, Glycerol$10 \mathrm{ml}, \mathrm{pH}-7.2$ ) and incubated for 24 hours at $37^{\circ} \mathrm{C}$ in an incubator.

The isolated Pseudomonas aeruginosa strain was tested for de-colorization activity against newly synthesized azo compounds $\left(0.250 \mathrm{gL}^{-1}\right)$ in nutrient broth $\left(\mathrm{gL}^{-1}\right.$ peptic digest of animal- $5 \mathrm{~g}$, sodium chloride- $5 \mathrm{~g}$, beef extract $1.50 \mathrm{~g}$, yeast extract- $1.50 \mathrm{~g}, \mathrm{pH}-7.4$ ) by inoculating with loop full bacterial culture. These flasks were incubated at $37^{\circ} \mathrm{C}$ for $24 \mathrm{hrs}$. Un-inoculated flasks served as controls to assess the abiotic decolorization. Optical densities values were measured spectrophotometrically at $418 \mathrm{~nm}$ and $377 \mathrm{~nm}$ respectively for the estimation involving de-colorization process.

\section{RESULTS AND DISCUSSION}

The newly synthesized azo compounds were characterized by using TLC, UV-Visible, FT/IR, ${ }^{1} \mathrm{H}$ NMR and ${ }^{13} \mathrm{C}$ NMR spectroscopy. The results obtained through these sophisticated techniques are well matched. In case IR appearance of band at 1579.75 and at 1581.68 indicate the formation $-\mathrm{N}=\mathrm{N}$ - bond in both compound $\mathrm{A}$ and compound $\mathrm{B}$ respectively. In case of ${ }^{1} \mathrm{H}$ NMR, the peak appears at $6.89 \mathrm{ppm}$ for $\mathrm{H}$ para with respect to $-\mathrm{OH}$ in salicyclic acid disappear in both compound $\mathrm{A}$ and compound $\mathrm{B}$, meaning there is coupling reaction takes place at this position

After 24 hrs of incubation with bacterial culture, the degraded azo compound A and B were scanned for HPTLC by comparing sulfacetamide as standard for degraded azo compound $A$ and sulfathiazole for degraded azo compound B. Fig.1. is the DensitometricHPTLC chromatogram of standard i.e. sulfacetamide, Fig.2. is Densitometric-HPTLC chromatogram of newly synthesized azo compound A after incubation for $24 \mathrm{hrs}$ and Fig.3 represents Densitometric-HPTLC 
chromatogram (comparable 3D view) in which first three peaks for standard and next three peaks are for degraded azo compound A. On comparison, it was found that the Rf value of standard sulfacetamide 0.93 exactly matched with $\mathrm{Rf}$ value of released drug from compound A (Table 1).

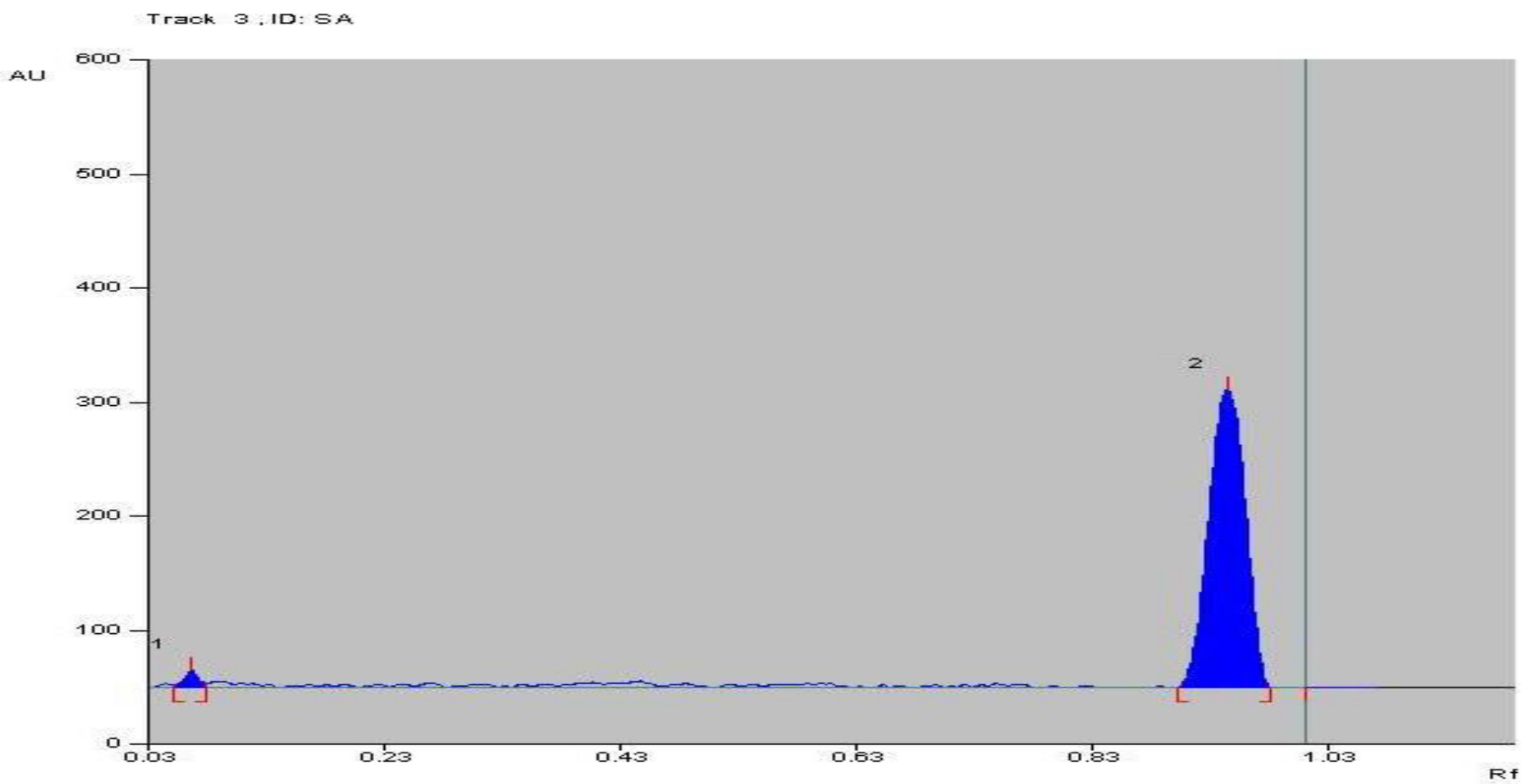

Fig. 1: Densitometric HPTLC chromatogram of pure sulfacetamide

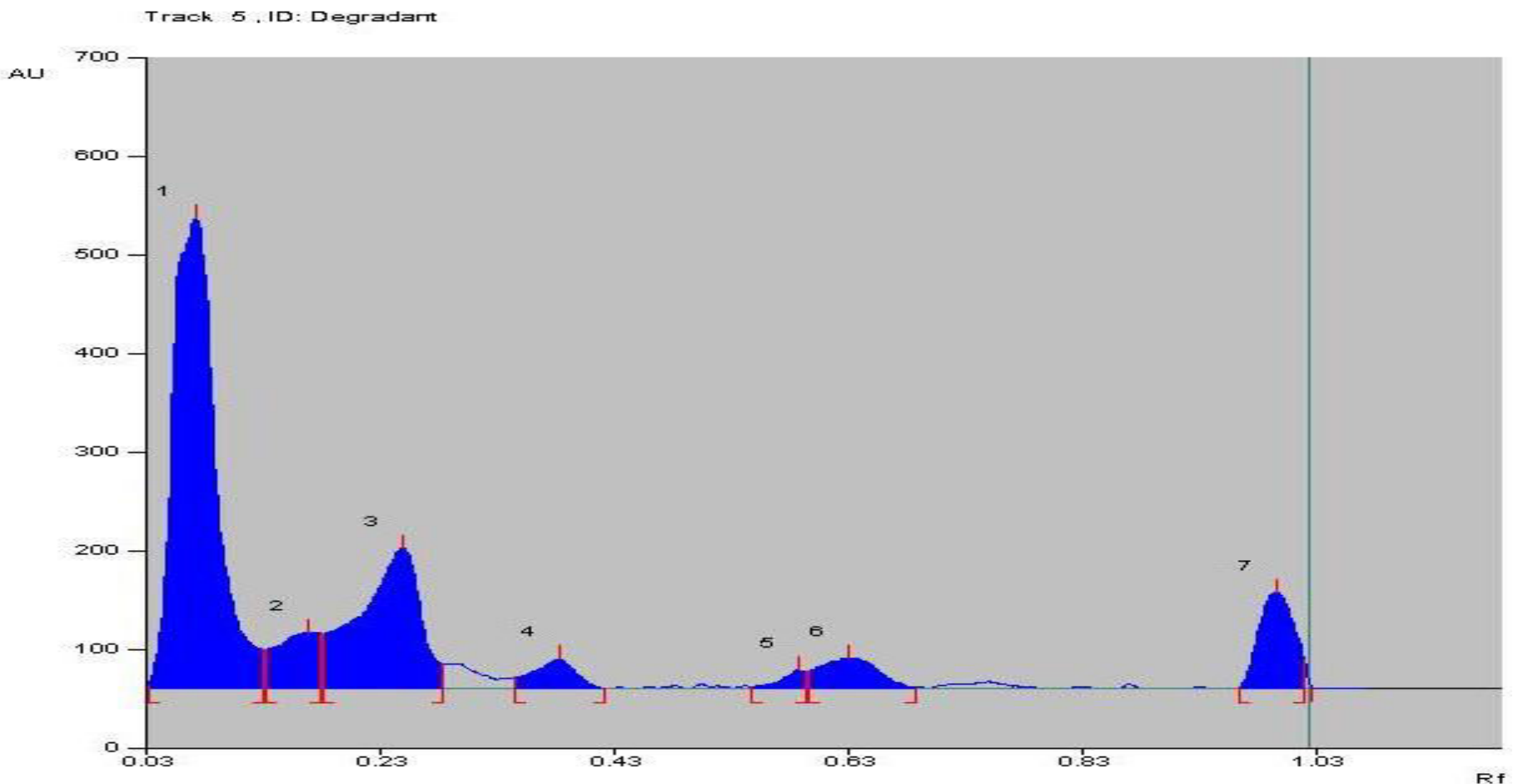

Fig. 2: Densitometric-HPTLC chromatogram of newly synthesized azo compound A after incubation of 24 hrs 


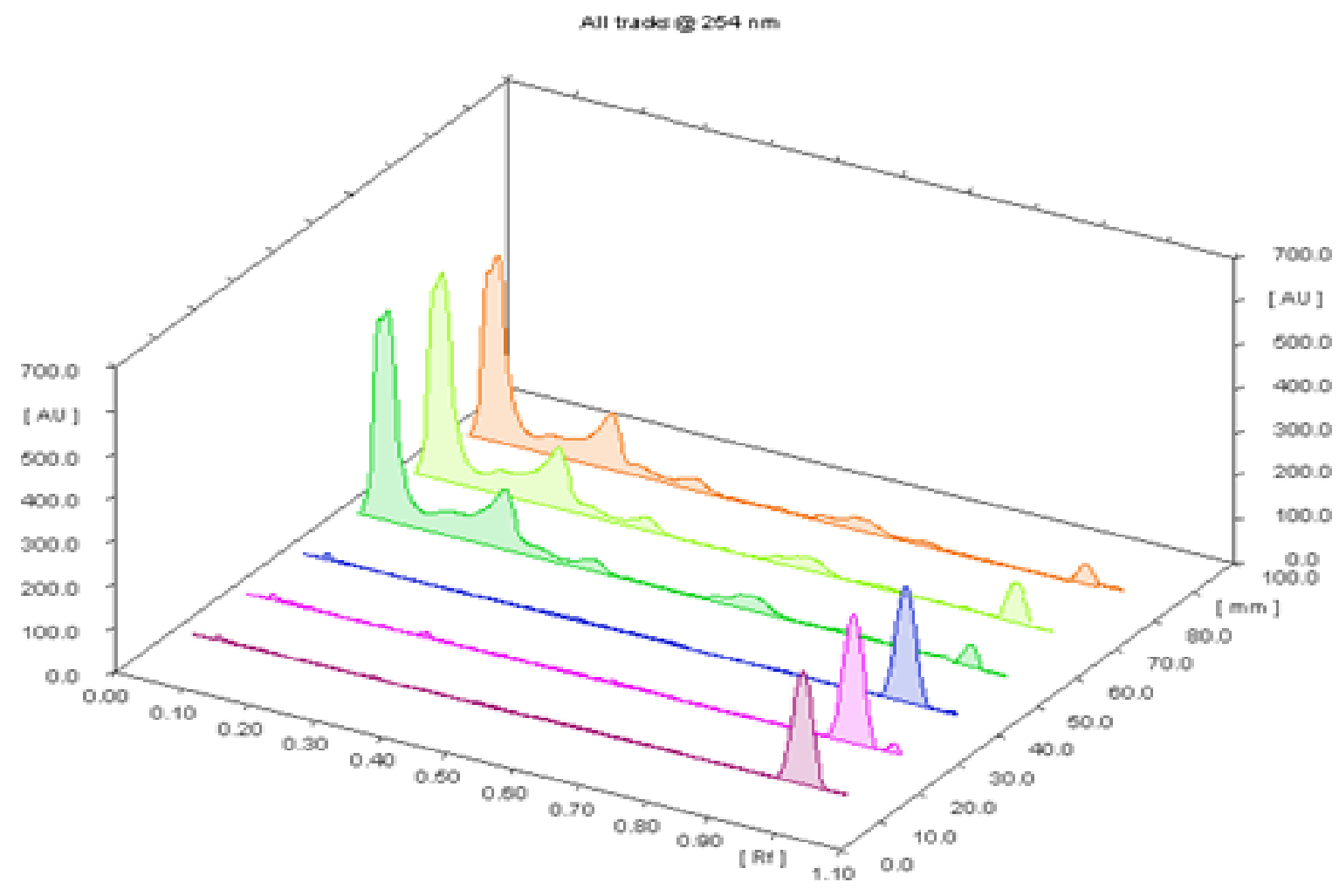

Fig. 3: Densitometric-HPTLC chromatogram of pure sulfacetamide and degraded azo compound A (comparable 3D view)

Table 1: Comparable Rf values of pure sulfonamides and drug released from azo compounds $A$ and $B$

\begin{tabular}{lcc}
\hline Compound & $\begin{array}{c}\text { Rf value of } \\
\text { drug released }\end{array}$ & $\begin{array}{c}\text { Rf value of pure } \\
\text { Sulfonamide derivatives }\end{array}$ \\
\hline Compd A & 0.93 & 0.93 (Sulfacetamide) \\
\hline Compd B & 0.83 & 0.83 (Sulfathiazole) \\
\hline (Source: Personal Collection, generated on CAMAG HPTLC \\
applicator 5, CAMAG HPTLC Scanner 3, WINCAT 1.3.O, S. S. V. \\
P. S's. L. K. Dr. P. R. Ghogrey Science College, 424 O05, Dhule (M. \\
S.) India)
\end{tabular}

Fig. 4. is the Densitometric-HPTLC chromatogram of standard i.e. sulfathiazole, Fig. 5. is the DensitometricHPTLC chromatogram of newly synthesized azo compound B after incubation for $24 \mathrm{hrs}$ and Fig.6 represents Densitometric-HPTLC chromatogram (comparable 3D view) in which first three peaks for standard and next three peaks are for degraded azo compound B. On comparison, it was found that the Rf value of standard sulfathiazole 0.83 exactly matched with $\mathrm{Rf}$ value of released drug from compound $\mathrm{B}$. These results suggested that when the compound $A$ and compound B were exposed to azoreductase enzyme, then the reduction of azo functional group $-\mathrm{N}=\mathrm{N}$ - takes place and two pharmaceutically active agents releases i.e. sulfacetamide, mesalamine and sulfathiazole, mesalamine respectively. This can be monitored by taking absorption spectra of inoculated compound $\mathrm{A}$ and compound B after each $2 \mathrm{hrs}$ of inoculation which is shown in table 2 and table 3 respectively. By ploting the graph of absorbance vs. time it gives a declined straight line (Fig.7, Fig 8).

Overlain UV spectra (Fig.9 and Fig.10) of degraded azo compound A and degraded azo compound B shows excellent identical peaks of standards and released drug respectively. UV spectral data of standard and degraded azo compounds is given in Table 4. The absorption spectra of standard (sulfacetamide) gives the peak at $277.0 \mathrm{~nm}$ and the degraded azo compound A also gives the peak at $277.0 \mathrm{~nm}$ in absorption spectra. It means there is release of sulfacetamide form degraded azo compound A along with mesalamine which may acts as mutual prodrug to each other. The absorption spectra of standard (sulfathiazole) and degraded azo compound B both shows peak at $289.0 \mathrm{~nm}$, suggested that, there is degradation of $-\mathrm{N}=\mathrm{N}$ - azo linkage as release of sulfathiazole and mesalamine from compound B. 


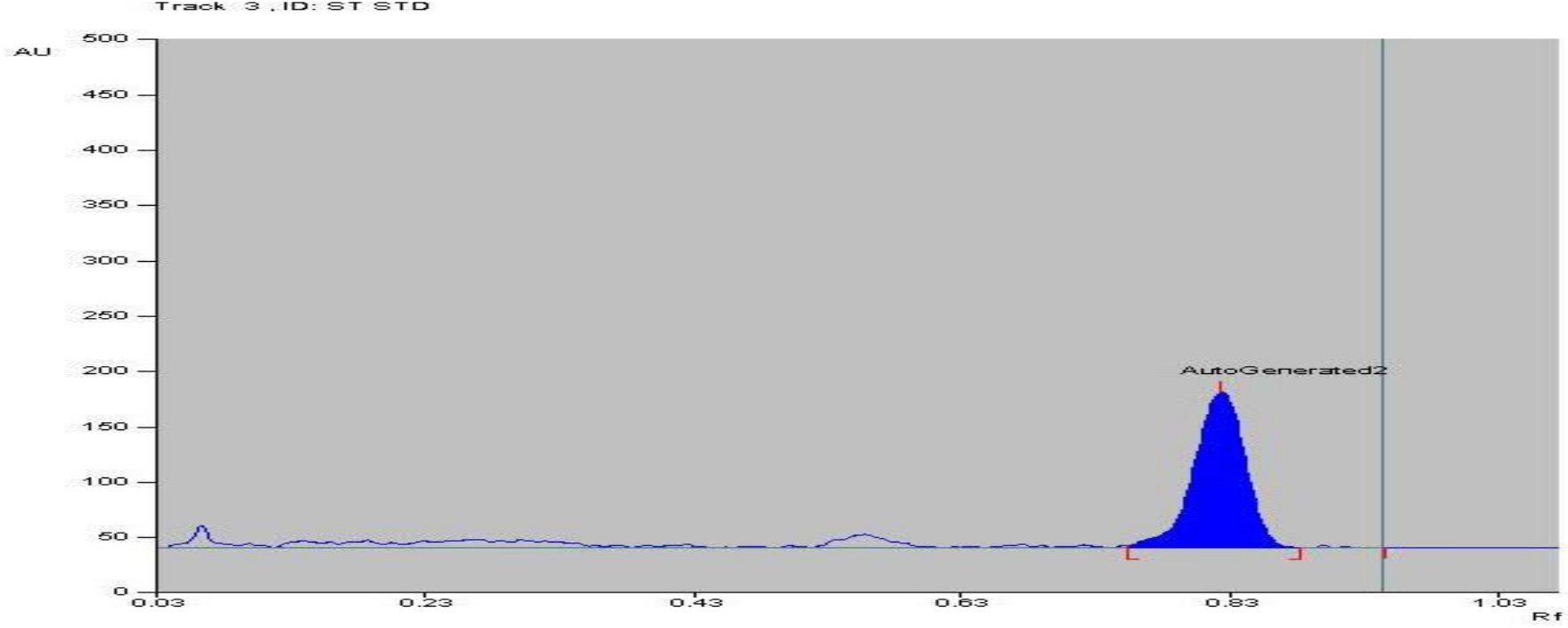

Fig. 4: Densitometric HPTLC chromatogram of pure sulfathiazole

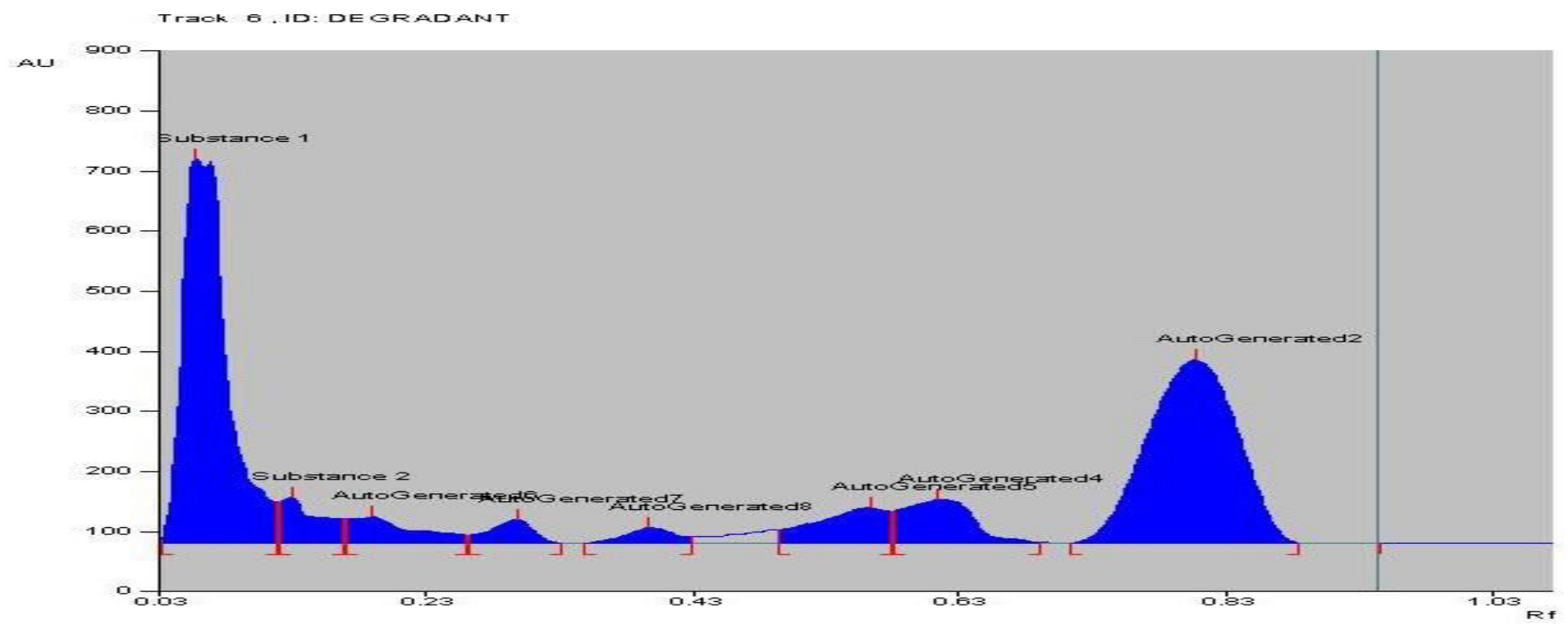

Fig.5: Densitometric HPTLC chromatogram of newly synthesized azo compound B after incubation of 24hrs

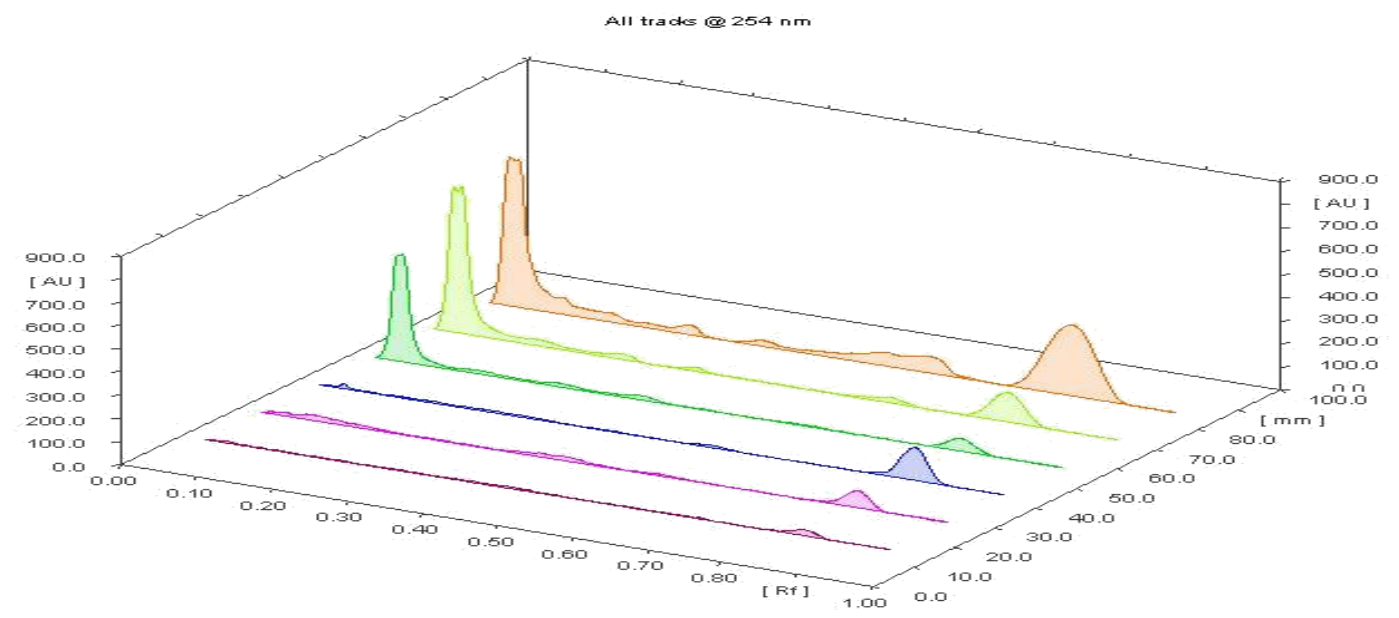

Fig. 6: Densitometric-HPTLC chromatogram of pure sulfathiazole and degraded azo compound B (comparable 3D view) 
Table 2: UV absorption data of newly synthesized azo compounds A at $418 \mathrm{~nm}$ after each 2 hrs.

\begin{tabular}{cc}
\hline Time in hours & Intensity \\
\hline 0 (at initial) & 2.995 \\
\hline 2 & 2.955 \\
\hline 4 & 2.81 \\
\hline 6 & 2.621 \\
\hline 8 & 2.41 \\
\hline 10 & 2.201 \\
\hline 12 & 1.998 \\
\hline 14 & 1.804 \\
\hline 16 & 1.615 \\
\hline 18 & 1.426 \\
\hline 20 & 1.289 \\
\hline 22 & 1.105 \\
\hline 24 & 0.998
\end{tabular}

Table 3: UV absorption data of newly synthesized azo compounds $B$ at $377 \mathrm{~nm}$ after each 2 hrs

\begin{tabular}{cc}
\hline Time in hours & Intensity \\
\hline 0 (at initial) & 2.889 \\
\hline 2 & 2.859 \\
\hline 4 & 2.621 \\
\hline 6 & 2.568 \\
\hline 8 & 2.421 \\
\hline 10 & 2.398 \\
\hline 12 & 2.298 \\
\hline 14 & 2.201 \\
\hline 16 & 2.104 \\
\hline 18 & 2.094 \\
\hline 20 & 1.924 \\
\hline 22 & 1.891 \\
\hline 24 & 1.801 \\
\hline
\end{tabular}

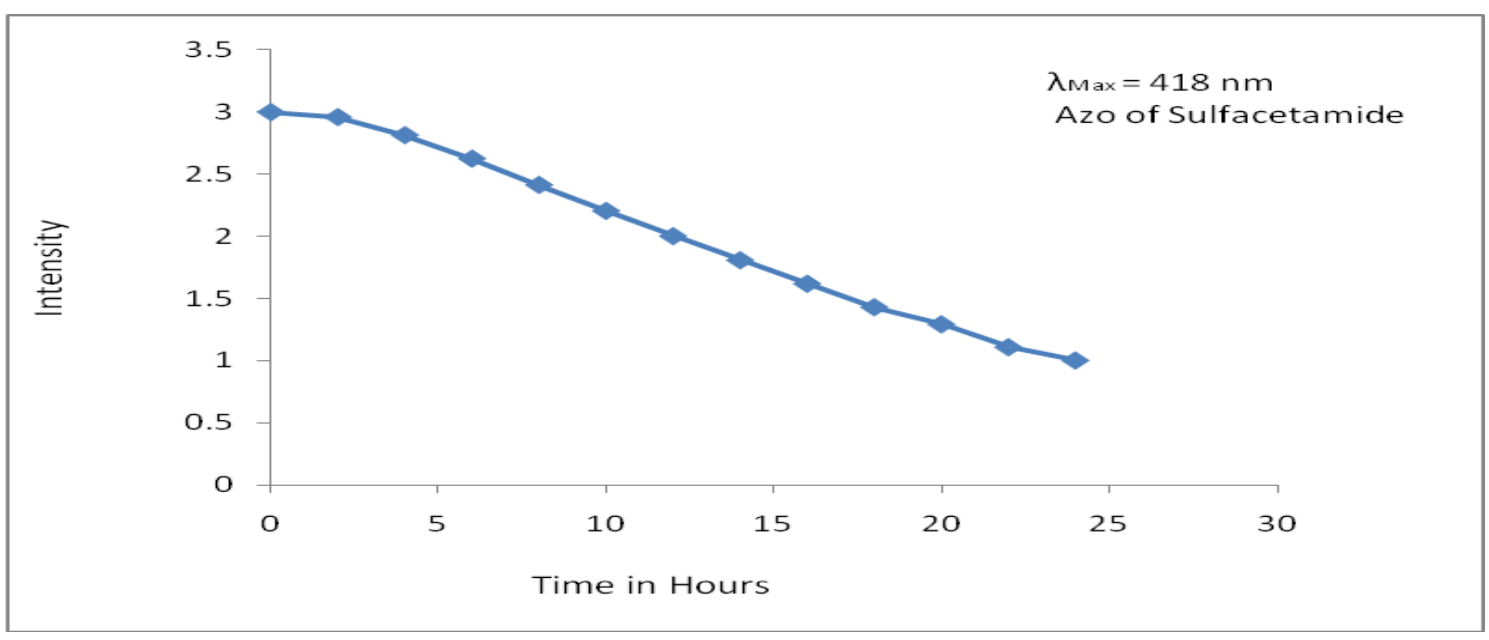

Fig. 7: Plot of intensity v/s time after inoculation of Pseudomonas aeruginosa bacterium species in azo of Compd A

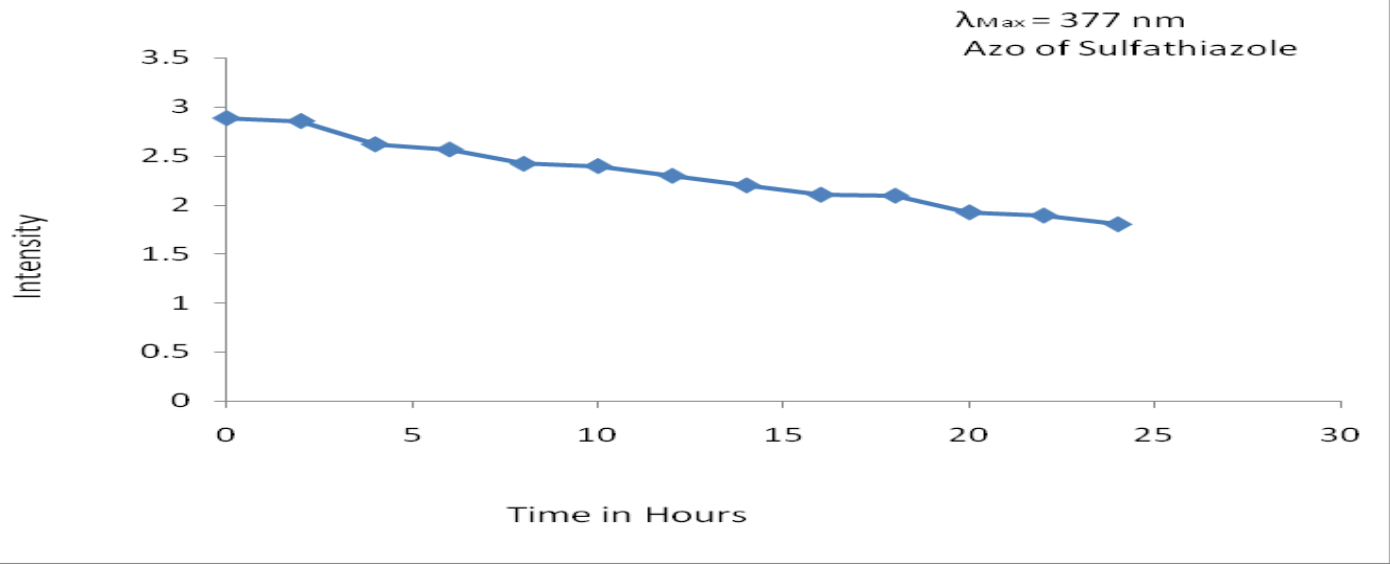

Fig. 8: Plot of intensity v/s time after inocula-tion of Pseudomonas aeruginosa bacterium species in azo of Compd B 
Spectra comparison

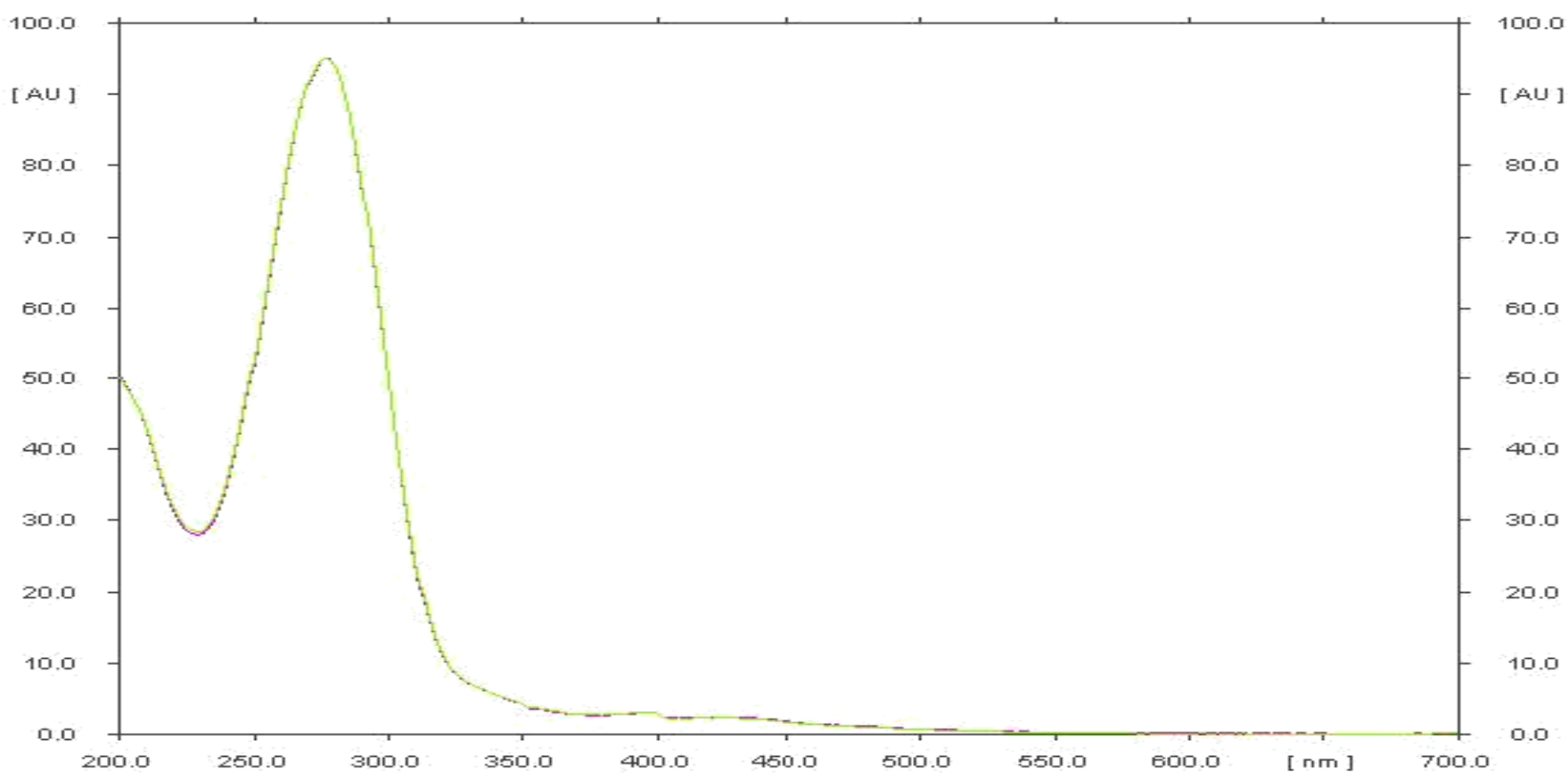

(Source: Personal Collection, generated on CAMAG HPTLC applicator 5, CAMAG HPTLC Scanner 3, WINCAT 1.3.0, S. S. V. P. S's. L. K. Dr. P. R. Ghogrey Science College,424 005, Dhule (M. S.) India)

Fig. 9: Overlain spectra of linearity found sulfacetamide in Compd A and with that of the standards during UV-AUC analysis

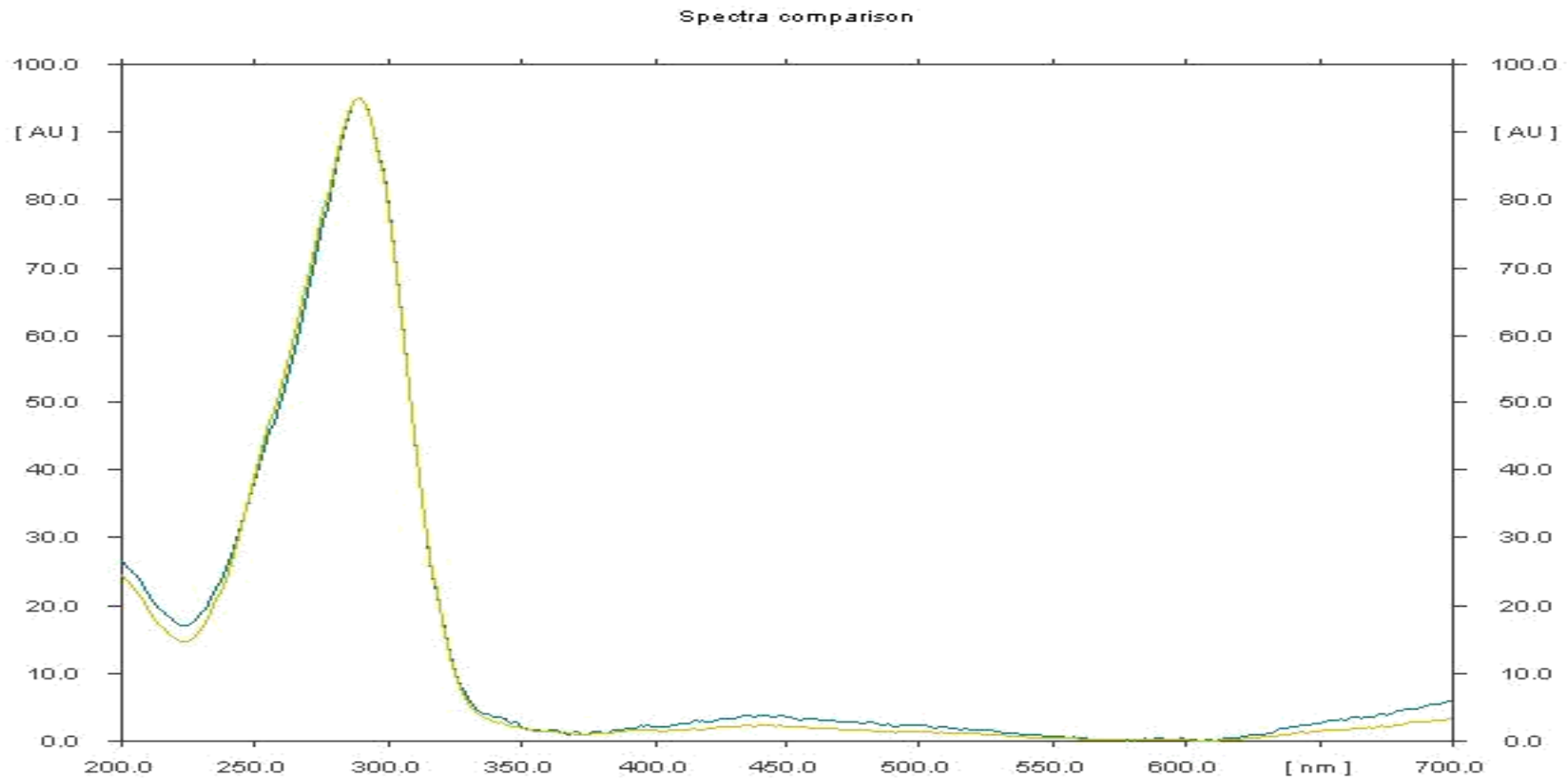

(Source: Personal Collection, generated on CAMAG HPTLC applicator 5, CAMAG HPTLC Scanner 3, WINCAT 1.3.0, S. S. V. P. S's. L. K. Dr. P. R. Ghogrey Science College,424 005, Dhule (M. S.) India)

Fig. 10: Overlain spectra of linearity found sulfathiazole in Compd B and with that of the standards during UV-AUC analysis 
Table 4: Comparable UV absorption values of pure sulfonamides and drug released from azo compounds A and B

\begin{tabular}{ccc}
\hline Compound & $\begin{array}{c}\text { UV absorption } \\
\text { value of drug } \\
\text { released }\end{array}$ & $\begin{array}{c}\text { UV absorption value } \\
\text { of pure Sulfonamide } \\
\text { derivatives }\end{array}$ \\
\hline Compd A & $277.0 \mathrm{~nm}$ & $277.0 \mathrm{~nm}$ \\
\hline Compd B & $289.0 \mathrm{~nm}$ & $289.0 \mathrm{~nm}$ \\
\hline
\end{tabular}

\section{Validation of Method}

The developed method was validated in accordance with ICH guidelines.

\section{Linearity and range}

Linearity was found in the range of 145 to 318 for compound A and 648 to 3108 for compound B. The released parent drug molecule peak areas were calculated at each concentration level and were shown in the graph of plot of concentration (ng/band) against peak area.(Fig. 11, Fig. 12).

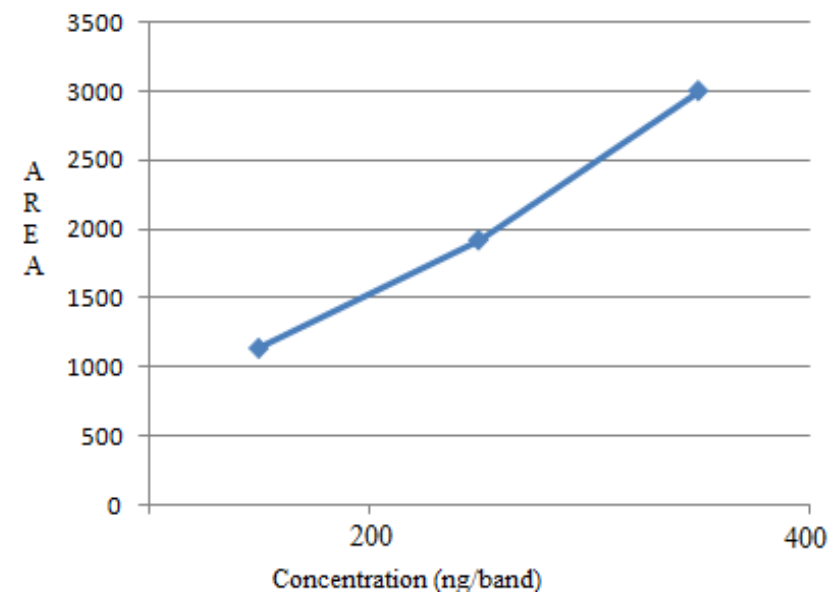

Fig. 11: Standard Calibration Curve (Compound A)

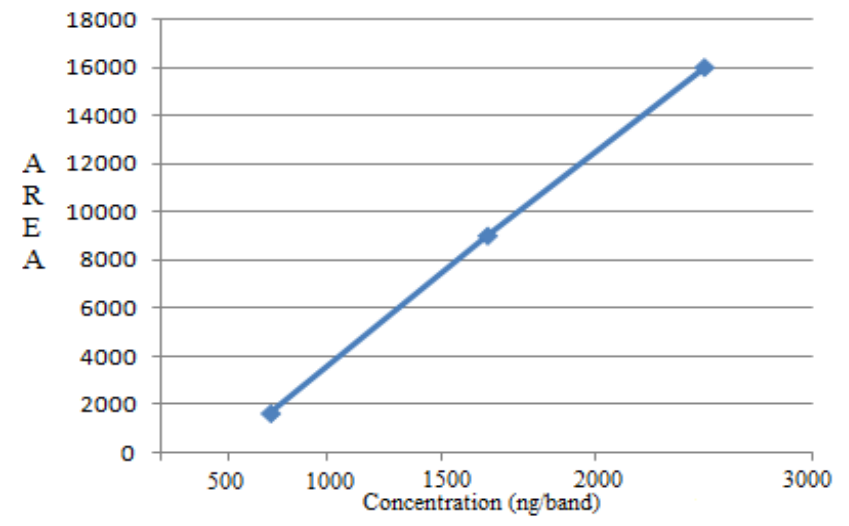

Fig. 12: Standard Calibration Curve (Compound B)

\section{Accuracy}

For the purpose of accuracy, standard addition method was employed in this method. The known amount of parent drug was added at 3 different levels to degraded compound A and compound B. Analysis was performed in triplicate at each level. The result of release of parent drug expressed in terms of $\%$ release. The $\%$ of release of parent compound from degraded compound $\mathrm{A}$ and degraded compound B was found to be nearly $99 \%$ indicating that there is no interference in the analysis shown in Table 5.

Table 5: Accuracy result

\begin{tabular}{ccc}
\hline Level of release & Release in \%* & Release in \%* \\
\cline { 2 - 3 } in \% & Compound A & Compound B \\
\hline $9.40 \%$ & 98.91 & 99.43 \\
\hline $20 \%$ & 98.93 & 99.48 \\
\hline $36.91 \%$ & 98.91 & 99.39 \\
\hline
\end{tabular}

* mean of three determinations

\section{Robustness}

The outcomes of change of mobile phase composition $( \pm 0.1 \mathrm{~mL})$, in chamber saturation period $( \pm 25 \%)$ in time of application to development (30 mins, 60 mins), in scanning time (30 mins, 60 mins), on peak areas, in $R_{f}$ values were considerd for robustness. It was seen that, in all mentioned factors, insignificant change is observed (\% RSD $<2$ for peak area, change in $\mathrm{R}_{\mathrm{f}}$ less than \pm 0.06$)$. Hence this in-vitro release study was said to be robust.

The significance of this study is that when the compound $\mathrm{A}$ and compound $\mathrm{B}$ were exposed to azoreductase enzyme, then the reduction of azo functional group $-\mathrm{N}=\mathrm{N}$ - takes place and two pharmaceutically active agents releases i.e sulfacetamide and mesalamine in compound A where sulfathiazole and mesalamine in compound B. Means here release of two potential pharmaceutical active agents via degradation from each other therefore they may acts as mutual prodrugs to each other.

\section{CONCLUSION}

In this study, azo derivatives of salicylic acid, sulfacetamide, sulfathiazole was synthesized, characterized and release study of parent drug also studied. The release of parent drug such as sulfacetamide and sulfathiazole was confirmed by HPTLC and UV-visible techniques. In addition to this mesalamine also released from both compound $\mathrm{A}$ as well as form compound B. This in-vitro study represents 
how the orally administered drug can be protected from upper GUT pH environment and safely reach to large intestine and colon. The colon microflora secretes different types of enzymes, out of which one is azoreductase and this enzyme is responsible for release of parent drug from azo prodrugs.. The synthesized new azo compounds does not absorbs and metabolized in upper part of GUT due to presence of $-\mathrm{N}=\mathrm{N}$ - azo linkage and different $\mathrm{pH}$ environment, which is only degraded in presence of azoreductase enzyme secreted at colonic part and metabolized only at colon.

Therefore, this method can acts as mutual prodrug strategy for each other. This mutual prodrug approach can open new doors in the field of medicinal chemistry and pharmaceutical chemistry especially for colon targeting treatments.

\section{ACKNOWLEDGEMENT}

The author is very thankful to Ishita Drugs \& Pharmaceuticals, Ahmadabad, Gujarat, India for supply of good quality of sulfonamide drug compounds. We are also thankful to Sophisticated Analytical Instrumentation Facility, Punjab University, Chandigarh, (Punjab) India for giving the ${ }^{1} \mathrm{H}$ NMR and ${ }^{13} \mathrm{C}$ NMR scanning facility.

\section{Conflict of interest}

This research did not receive any specific grant from funding agencies in the public, commercial, or not-forprofit sectors.

\section{REFERENCES}

1. Rautio J, Kumpulainen H, Heimbach T, Oliyai R, Oh D, Jarvinen R, Savolainen J. Nature publishing group -Drug discovery, 2008; 7:255-270.

2. Patil SJ, Shirote PJ. Int J Med Pharm Sci, 2011; 1(7): $1-13$.

3. Helish SO, Ebersole JL. Mole, 2008; 13(4):771.

4. Lawrence H, Mundsen A. J. Chem. Educ, 1942; 19(4):167.
5. Wang S, Zhang YH, Wang L, Duan ZJ, Kennedy I. Food Additives \& Contaminants, 2006; 23(4):362-384.

6. Pavia DL, Lampman GM, Kriz GS, Engall RG. Thompson Books/ cole, $2^{\text {nd }}$ ed. 2005. p. 376-79.

7. May JAMd, Maddh QAK, Amera AMd, Faris AA, Hussain AMd, Int $J$ Compre Pharm, 2012; 3, 6 (02):1-4.

8. Philippe D, Dodd RH. A. Chem. Soc, org lett, 2000; 2(15):2327-2329.

9. Tomczak EW, Gorecki L. Chemik, 2012; 66(12):1298-1307.

10. Damagk G. Chemotherapy, 1935; 61:250-253.

11. Conning DM, Lansdown ABG. Toxic hazards in food, Springer science \& business media, 233.

12. Garjani A, Davaran S, Rashidi RMd, Maleki N. DARU J Pharm Sci, 2004; 12(1):24-30.

13. Kaiser GC, Yan F, Polk DDB. Gastroenterology, 1999; 116:602-609.

14. Eshron P, Ligumsky M, Rachmilewitz D, Zor U. Gastroenterology, 1978; 75:638-640.

15. Hanumantharao K, LakshmanaRao A, Chandrasekhar KB. International Journal of Research in Pharmacy and Chemistry, 2013; 3(2):472-476.

16. Professionals Medfacts, Mesalamine, https://www. drugs.com/ppa/mesalamine.html (accessed 21 December 2016)

17. Mesalamine-tablet article, Mesalamine (5-amino salicylic acid) delayed release -oral, Asacol, Delzicol, https://www.medicinenet.com/ mesalamine-tablet/article.html (accessed 22 December 2016)

18. Koshti SM, Sonar JP, Sonawane AE, Pawar YA, Nagle PS, Mahulikar PP, More DH. Ind J Chem, 2008; 47(B):329-331.

19. Koshti SM, Patil PA, Patil CB, Patil AS. Der Phar Chem, 2019; 10(12):1-15.

20. Swain SS, Paidesetty SK, Padhy RN. Biomed Pharmacotherapy, 2017; 88:181-193.

21. Vijaya PP, Aishwaryalakshmi R, Yogananth N, Syed Ali M. J. Adv. Lab. Res. in Bio., 2012; 3(4):285-289. 